\title{
Luis Ortega
}

Catedrático de Derecho Administrativo

Universidad de Castilla-La Mancha

\section{El Alcalde como elemento de la organización municipal}

SUMARIO: 1. NOTAS CONSTITUCIONALES DE LA FIGURA DEL ALCALDE. 2. LA POSICION PREFERENTE DEL ALCALDE EN RELACION AL SISTEMA DE FUENTES QUE REGULE LA ORGANIZACION MUNICIPAL. 3. EL DESDOBLAMIENTO ORGANICO Y FUNCIONAL DE LA FIGURA DEL ALCALDE. 4. LA POSICION DEL ALCALDE EN EL SENO DEL AYUNTAMIENTO-ENTE. 5. LA POSICION RELATI. VA ENTRE ALCALDE Y PLENO EN CUANTO ORGANOS DEL AYUNTAMIENTOENTE. 6. EL ALCALDE EN CUANTO PRESIDENTE DEL AYUNTAMIENTO-ENTE. 7. EL ALCALDE EN CUANTO TITULAR DEL ORGANO DE DIRECCION GUBERNATIVA Y ADMINISTRATIVA DEL AYUNTAMIENTO. 8. EL ALCALDE COMO MIEMBRO PRESIDENTE DE LOS ORGANOS COLEGIADOS MUNICIPALES. 9. CONCLUSIONES.

\section{NOTAS CONSTITUCIONALES DE LA FIGURA DEL ALCALDE}

La escueta regulación constitucional de nuestro Régimen Local no está exenta de claves que aportan decisiones fundamentales para la correcta interpretación de la organización municipal. Entre ellas destacan dos que se refieren a la figura del Alcalde. De una parte se institucionaliza el Alcalde como órgano municipal; de otra se establece su carácter democrático y representativo.

Es evidente que ambos elementos forman parte del contenido de la garantía institucional predicable de los Municipios ${ }^{1}$ y que, por ende,

1 Por todos, Parejo: Garantía institucional y autonomias locales, IEAL, Madrid, 1981.

Documentación Administrativa / n." 228 (octubre-diciembre 1991) 
son elementos indisponibles para el legislador, que los deberá siempre respetar.

La institucionalización del Alcalde como elemento de la organización municipal no se hace de cualquier manera, sino de forma tal que soluciona su posición dentro del conjunto de dicha organización. En efecto, en el artículo 140 de la Constitución leemos que el gobierno y administración de los Municipios corresponde a sus respectivos Ayuntamientos, integrados por los Alcaldes y los Concejales. De esta forma la Constitución ordena en tan escueto mandato tres elementos capitales: que los órganos municipales no son órganos del Estado sino representativos de la propia colectividad local; que el Ayuntamiento es la institución que globaliza la expresión de la organización municipal; y que, dentro de esta organización, el Alcalde es un elemento necesario de la misma. Como ha destacado Morrell ${ }^{2}$, esta ordenación constituye un «significativo giro» respecto del modelo del franquismo, en el cual el Municipio se concebía como un órgano estatal y su organización se instalaba en una bicefalía formal entre Alcalde y Ayuntamiento y en una posición preeminente del primero respecto del segundo. Según el mencionado autor, «se recobra, de este modo, una tradición legislativa y una concepción institucional...: la de definir el Ayuntamiento como la institución que asume los fines del Municipio y actúa en representación de la colectividad local... Ahora el Alcalde es un órgano del Ayuntamiento y es éste el que asume la representación de la colectividad local y, en nombre de ella, el gobierno y la administración del Municipio».

Sin embargo, dentro de esta nueva configuración, la constitucionalización de la figura del Alcalde añade algún elemento más. Si la garantía institucional asegura «la preservación de una institución en términos recognoscibles para la imagen que de la misma tiene la conciencia social de cada tiempo y lugars ${ }^{3}$, ello implica que la figura del Alcalde tiene un determinado sentido del que no es posible prescindir. Dentro de los parámetros antes expresados —órgano del Ayuntamiento y carácter representativo--, y que por tener rango constitucional remodelan los elementos de la institución, la aplicación de la garantía institucional a la figura del Alcalde nos conduciría a la recognoscibilidad de determinadas notas características. Entre ellas, sin duda, destacan dos: la de asumir la presidencia del órgano colegiado que expresase la representación general del Ayuntamiento -el Pleno-; y la de poseer competencias propias dentro del entramado institucional del Ayuntamiento. Por la propia construcción constitucional del nuevo Régimen Local basado en el concepto de autonomía y en la representatividad

2 MORELL: El régimen local español, Civitas, Madrid, 1988, pp. 468 y ss.

3 STC de 18 de junio de 1981, fundamento jurídico núm. 3. 
directa de la colectividad local, no forma parte del concepto constitucional de Alcalde su cualidad de delegado del Gobierno en el Municipio ${ }^{4}$.

El segundo elemento de la garantía institucional referida a la figura del Alcalde es, como antes se señalaba, su carácter democrático y representativo. Este dato añade importantes cuestiones a la organización municipal muchas de los cuales están aún por desarrollar. Así, a mi juicio, no se han extraído aún las consecuencias derivadas del hecho de que no se trata de una Administración vicarial, como se predica de la Administración del Estado, sino directamente representativa de su comunidad ordinamental. Sin embargo, aquí nos interesa destacar que este carácter electivo tiene importantes consecuencias organizativas desde la perspectiva del pluralismo político concurrente a las elecciones municipales y la regla democrática del gobierno de la mayoría.

Sabemos que la Constitución permite una doble fórmulal electiva, «por los Concejales o por los vecinos». La Ley electoral ha optado por la primera fórmula (art. 196 LOREG) con alguna concesión residual a la segunda. En efecto, el Alcalde debe ser elegido por la mayoría absoluta de los votos de los Concejales (primera fórmula) si bien el elector sabe que sólo puede ser candidato el cabeza de lista y que, caso de que nadie obtenga dicha mayoría absoluta, se proclama Alcalde al cabeza de la lista que haya obtenido más votos. Pero, en definitiva, el Alcalde obedece a la confianza de la mayoría absoluta de Concejales, por lo que si, a veces, se utiliza la expresión de presidencialismo para significar la posición institucional del Alcalde, en la realidad, el Alcalde es fruto del sistema de democracia parlamentaria. Por ello, el Alcalde representa necesariamente a la mayoría, de forma explícita, cuando obtiene el voto de la mayoría absoluta de los Concejales, o de forma implícita, cuando al cabeza de la lista más votada no se le opone ninguna otra mayoría absoluta. De aquí se desprenden dos reglas organizativas: la regla del pluralismo en la representación del conjunto de los Concejales y la regla de la mayoría en la figura del Alcalde.

4 Desaparece, así, una de las notas característica de la construcción del régimen local napoleónico tal como fue destacado por GARCla DE ENTERRfa: «La construcción napoleónica es la esencial, la que alcanzó una suerte definitiva e inconmovible, y consistió nada más que en establecer esa articulación inexistente entre los entes locales y el Estado por medio de una técnica organizativa tan perfectamente simple como efectivamente luminosa y genial: la técnica de reservar la esfera de la acción a una línea de agentes monocráticos o individuales ligados precisamente por el vínculo de la jerarquía desplazando lateralmente las corporaciones colegiales a un simple papel de deliberación y de consejos (La Administración española, Alianza Editorial, Madrid, 1985, p. 71). 


\section{LA POSICION PREFERENTE DEL ALCALDE EN RELACION AL SISTEMA DE FUENTES QUE REGULE LA ORGANIZACION MUNICIPAL}

Antes de abordar el análisis de la figura del Alcalde dentro de la organización municipal contemplada por la LRBRL, quisiera apuntar algunas consecuencias derivadas de la aplicación del sistema de fuentes a la materia de organización local.

Una de las reglas de toda ley básica consiste, como es sabido, en que su contenido normativo no agota la totalidad de la materia, lo que es predicable a la materia organizativa del Régimen Local. A su vez, al ser la capacidad de autoorganización uno de los elementos del principio de autonomía de que gozan los entes locales, la regulación del sistema de fuentes en relación a la organización local goza de una cierta complejidad ${ }^{5}$.

No se trata de adentrarnos en dicho tema, sino partir del dato de que la regulación de la figura del Alcalde que se contempla en la LRBRL puede ser completada por la legislación autonómica y por la propia capacidad de autoorganización de cada ente local ${ }^{6}$. Dentro de este marco, la LRBRL, además de considerar al Alcalde como un órgano necesario de todo Municipio [art. 20.1.a)], tema sobre el que luego volveremos, sitúa al Alcalde en una posición preferente respecto de los demás órganos, especialmente respecto del Pleno, en relación al ejercicio de la potestad normativa que puedan efectuar los legisladores sectoriales ya sean estatal o autonómico. Esta posición preferente se manifiesta en que opera a su favor el juego de la cláusula residual de competencias, al establecerse en el artículo 21.1. $\mathrm{m}$ ) como competencia del Alcalde «aquellas que la legislación del Estado o de las Comunidades Autónomas asignen al Municipio y no atribuyan a otros órganos municipales». Si tenemos en cuenta que, como ha señalado MuÑoz MACHADO, «en el artículo 148 de la Constitución, donde se delimita el núcleo mínimo de materias disponibles para todas las Comunidades $\mathrm{Au}$ tónomas, aparecen la mayor parte de los asuntos sobre los que tradicionalmente han tenido competencias los entes locales $o$, dicho de otra forma, materias en las que el interés local, además del regional, parece de forma evidentes ${ }^{7}$. Por ello, la importancia del ámbito de la legis-

5 Véase en este sentido MerCADAl VIDAL: "Organización municipal», en Tratado de Derecho Municipal, Civitas, Madrid, 1988, vol. I, pp. 865 y ss.

6 Tras la STC de 29 de diciembre de 1989, en la que se declara inconstitucional el artícu105 y parcialmente el artículo 20 , queda claro que la potestad municipal de autoorganización está sometida a lo dispuesto por el legislador autonómico.

7 Muñoz MaCHADo, Derecbo público de las Comunidades Autónomas, vol. II, Cívitas, Madrid, 1984, p. 198. 
lación sectorial autonómica como elemento de cierre del sistema competencial local realza el valor de la cláusula residual en favor del Alcalde. Este valor aumenta todavia en la medida en que la inteligencia de la norma debe conducir a que, junto a la indicación del fin público, se señale la forma de realizarlo o alcanzarlo, por lo que la cláusula residual puede introducir no sólo elementos competenciales materiales sino formas organizativas relativas al fin material perseguido ${ }^{8}$.

También desde la perspectiva de las potestades de autoorganización reconocidas en el artículo 4.1.a) LRBRL y partiendo de la posición de mayoría que arropa a la figura del Alcalde, ésta goza de una potencialidad de expansión de sus funciones en la organización complementaria que se pueda crear en base al cumplimiento de los fines municipales. En efecto, según el artículo 1 el Municipio institucionaliza y gestiona con autonomía los intereses propios de la colectividad local. Según el artículo 11.1 el Municipio tiene plena capacidad para el cumplimiento de sus fines. Según el artículo 28 el Municipio puede realizar actividades complementarias de las propias de otras Administraciones Públicas. Desde esta perspectiva, acompañada de la atribución legal de la dirección del gobierno y administración municipales operada en el artículo 21.1.a) LRBRL, la expansión organizativa del Municipio supondrá coherentemente un aumento de la posición relativa del Alcalde dentro del cuadro organizativo municipal.

\section{EL DESDOBLAMIENTO ORGANICO Y FUNCIONAL DE LA FIGURA DEL ALCALDE}

Sin entrar todavía en las relaciones entre Alcalde y Pleno, debe destacarse previamente el desdoblamiento orgánico y funcional de la figura del Alcalde. De una parte, el Alcalde constituye por sí mismo un órgano unipersonal del Ayuntamiento, órgano que, recordémoslo, goza de garantía institucional. Así lo recoge la LRBRL en sus artículos 19.2, 20.1.a), y 21. Pero, al mismo tiempo, integra y preside el resto de los órganos colegiados municipales, tanto el Pleno y la Comisión de Gobierno como cualesquiera otros que se pudiesen crear [art. 21.1.c) LRBRL]. Ello puede originar alguna confusión en orden al ejercicio de las respectivas competencias, más aún si se tiene en cuenta que cabe la posibilidad de que el Alcalde delegue sus propias competencias en alguno de los mencionados órganos colegiados. Esta confusión com-

8 Como señala CASSESE, «toda la administración (organización, personal, financiación y actividad) debe estar en relación congruente con los fines públicos... Esta relación no afecta -como se afirma generalmente - sólo a la actividad. Tampoco la organización, ni los demás elementos de la Administración Pública, pueden disociarse del fin público, con el cual están en una conexión de relación necesaria» (Le basi del diritto amministrativo, Einaudi, Turín, 1989, p. 83). 
petencial puede producirse en relación a determinados acuerdos de contenido complejo, donde una parte de su contenido pueda corresponder a las competencias del Alcalde y otra a las del Pleno. Un ejemplo lo constituye la negociación colectiva funcionarial, ya que en virtud artículo 35 de la Ley 9/1987, el Alcalde en el ejercicio de sus competencias propias en materia de personal puede llegar a suscribir Pactos, mientras que si la negociación versa también sobre competencias del Pleno, ello debe dar lugar a un Acuerdo. Sin embargo, existe una práctica que es la de aprobar por el Pleno el contenido total del convenio suscrito.

Otra faceta de desdoblamiento, la encontramos en el hecho de que el Alcalde es un órgano necesario y sometido, por tanto, a la regulación externa de sus funciones, pero, al mismo tiempo, el ordenamiento otorga al Alcalde potestades de nombramiento de los componentes de determinados órganos municipales como los Tenientes de Alcalde y los miembros de la Comisión de Gobierno (arts. 21.2 y 23.1 LRBRL) lo cual indudablemente refuerza su capacidad de dirección política ${ }^{9}$.

A mi juicio, aunque, como a continuación veremos, no cabe situar en la Alcaldía todas las potestades de gobierno, ya que el Pleno también tiene potestades ejecutivas, este doble desdoblamiento del Alcalde como órgano propio y miembro-Presidente del resto de los órganos municipales y con capacidad de configuración nominal de los miembros de determinados órganos de gobierno, le dotan de una posición privilegiada dentro de la organización municipal.

\section{LA POSICION DEL ALCALDE EN EL SENO DEL AYUNTAMIENTO-ENTE}

La tradicional configuración de nuestro Régimen Local ha dado un giro tan absoluto tras la Constitución de 1978 que es difícil enfocar adecuadamente la nueva situación si no partimos de una profunda revisión conceptual.

En nuestro modelo clásico de tradición napoleónica el Alcalde ha sido siempre, esencialmente, un elemento de la organización estatal. Ahora es un órgano de un ente complejo que es el Ayuntamiento, el cual se reputa representante de la comunidad política local. Siendo, a su vez, como ya se ha dicho, el Alcalde el líder político de la mayoría de los Concejales.

9 SOSA WAGNER ha destacado este hecho como una de las principales inversiones de tendencia en la tradición municipal española y, al mismo tiempo, el principal signo de reforzamiento de la posición del Alcalde en el ámbito de los Ayuntamientos [ «Los principios de la Ley Básica de Régimen Local», en Organización Territorial del Estado (Administración Local), vol. I, Instituto de Estudios Fiscales, 1985, p. 53]. 
Igualrnente, de los Municipios se ha predicado únicamente su papel como administración y su autonomía limitada al estrecho margen del pouvcir municipal. Sin embargo, el reconocimiento constitucional de su autonomía, entendida como un derecho de la comunidad local a la participación en cuantos asuntos le atañen ${ }^{10}$ y la atribución al Ayuntamiento del gobierno y administración de los Municipios, dota a sus entes representativos de una capacidad de dirección política dentro del nivel de expresión que el ordenamiento les reconoce.

La primera transformación citada, la desaparición de la concepción del Alcalde como un delegado del Gobierno central, ha tenido su manifestación en la eliminación de las potestades de control jurídico del Alcalde sobre los actos de los demás órganos de la Corporación ${ }^{11}$.

La seģunda plantea, a su vez, una nueva reordenación de las posiciones tradicionales de los órganos municipales. El Ayuntamiento, a diferencia del Estado o las Comunidades Autónomas, integra como organización el conjunto del poder público local y contiene la doble función representativa y ejecutiva ${ }^{12}$, de la cual participan igualmente sus dos órganos principales: el Alcalde y el Pleno del Ayuntamiento, el cual ya no es un mero colegio deliberante de apoyo al ejecutivo local personificado en el Alcalde. De aqui que sea necesario clarificar algunas nociones.

Si nos atenemos a la LRBRL tenemos los siguientes postulados legales:

- El Municipio tiene personalidad jurídica y plena capacidad para el cumplimiento de sus fines (art. 11.1).

- Son elementos del Municipio el territorio, la población y la organización (art. 11.2).

- El gobierno y administración municipal corresponde al Ayuntamiento (art. 19.1).

- El Ayuntamiento está integrado por el Alcalde y Concejales (art. 19.1).

- El Alcalde es el Presidente de la Corporación (art. 21.1).

- El Alcalde dirige el gobierno y la administración municipal [art. 21.1.a)].

10 STC de 28 de julio de 1981, fundamento jurídico núm. 4.

1 Ya RAZQUIN LIZARRAGA señalaba que, con las modificaciones introducidas tras la publicación del Real Decreto-ley 3/1981 y del Real Decreto 1262/1981, había desaparecido la potestad de los Presidentes de las Corporaciones Locales de suspender los acuerdos de sus órganos colegiados («El nuevo régimen de suspensión de acuerdos locales», RVAP, núm. 1, 1981, pp. 125 y ss.).

12 Como señala MORELL, «es, pues, una sola y unitaria organización la que, en las mismas, asume la representación y administración de la colectividad» (op. cit., p. 430) y, más adelante, «la legalidad ordinaria identifica, por otra parte, al Ayuntamiento con dos notas caracterizadoras: la de constituir una Corporación y, desde otra perspectiva, ser el elemento organización de los integrantes del Municipio» (op. cit., p. 469). 
- El Alcalde representa al Ayuntamiento [art. 21.1.b)].

- El Alcalde ejercita acciones judiciales y administrativas en caso de urgencia [art. 21.1.i)].

- El Pleno está integrado por todos los Concejales (art. 22.1).

- El Pleno es presidido por el Alcalde (art. 22.1).

- El Pleno acepta las delegaciones de competencias hechas por otras Administraciones Públicas [art. 22.2.g)].

- El Pleno plantea los conflictos de competencias a otras Entidades Locales y demás Administraciones Públicas [art. 22.2.b)].

- El Pleno ejercita las acciones administrativas y judiciales [art. 22.2.j)].

Además de estos postulados de la LRBRL, hay que tener en cuenta otros tres derivados del Texto Refundido de las disposiciones legales vigentes en materia de Régimen Local:

- Los Ayuntamientos, en representación de los Municipios y para el cumplimiento de sus fines tienen plena capacidad jurídica para adquirir, poseer, reivindicar, permutar, gravar o enajenar toda clase de bienes, celebrar contratos, establecer y explotar obras y servicios públicos, obligarse, interponer los recursos establecidos y ejercitar las acciones previstas en las leyes (art. 1).

- El Alcalde publica, ejecuta y hace cumplir los acuerdos del Ayuntamiento [art. 24.g)].

- El Pleno ostenta la defensa en los procedimientos incoados contra el Ayuntamiento [art. 23.f)].

El resultado de todos estos postulados puede resumirse del modo siguiente. El Municipio, en tanto que ordenamiento territorial, está dotado de personalidad jurídica. El Ayuntamiento, en tanto que organización del ordenamiento municipal, también está dotado de personalidad jurídica. Se produce, así, una doble entificación, la de contenido general del Municipio y la de contenido especializado, en cuanto elemento-organización, del Ayuntamiento. A su vez, el Ayuntamiento es una persona jurídica de carácter corporativo basado en la representación política de sus miembros - los Concejales-, con dos órganos de expresión: el Alcalde y el Pleno. Uno de estos órganos —el Alcalde-, es representativo por la regla democrática de la mayoría, ostenta la presidencia del ente Ayuntamiento-Corporación, su representación exterior de carácter político-institucional y expresa hacia el exterior, en las materias a él atribuidas, la voluntad jurídica del Ayuntamiento-ente. Otro de los órganos —el Pleno- se define por la reunión colegiada de los miembros de la Corporación, es representativo por la regla democrática del pluralismo y expresa también hacia el exterior, según la distribución legal de competencias, la voluntad del Ayuntamiento-ente 
a través de su Presidente, cargo que, mediante la técnica de la unión personal, recae en el titular de la Alcaldía.

Sólo a la vista de este cuadro se puede entender que el Alcalde sea el Presidente del Ayuntamiento-ente y, en cuanto tal, le corresponda la representación del Ayuntamiento [art. 21.1.b)], representación que es de carácter político-institucional. Es decir singulariza, por su presidencia del ente, el conjunto de la organización hacia el exterior y, al ser la organización el elemento instrumental del Municipio, el Alcalde acaba singularizando la representación exterior del Municipio.

Pero, al mismo tiempo, el Alcalde es un órgano unipersonal del Ayuntamiento-ente, que, en cuanto tal, tiene atribuidas competencias en cuyo ejercicio se vincula hacia el exterior a la persona jurídica Ayuntamiento-ente.

Finalmente, en cuanto que miembro cualificado de otro órgano del Ayuntamiento, el Pleno, al asumir su presidencia, es el encargado de exteriorizar las competencias reservadas a éste.

\section{LA POSICION RELATIVA ENTRE ALCALDE Y PLENO EN CUANTO ORGANOS DEL AYUNTAMIENTO-ENTE}

Una vez despejada la situación de la figura del Alcalde con relación al Ayuntamiento, podemos abordar una situación concreta, que presenta algún interés, la situación en que quedan entre sí Alcaldía y Pleno, ambos como órganos del Ayuntamiento.

Por el hecho de que toda la organización se concreta en el Ayuntamiento (el hecho de su personificación es intrascendente a estos efectos) hace que éste, en cuanto organización del Municipio-ordenamiento, ostente las atribuciones de poder público que le permite el ordenamiento constitucional: potestades de normación secundaria y de ejecución administrativa.

Trasladada esta situación al reparto de dichas potestades entre Alcaldía y Pleno, hay que concluir con MerCadal ${ }^{13}$ que «el Pleno es el órgano supremo de gobierno y administración municipal». En efecto desde el punto de vista de su posición institucional relativa, el Pleno ostenta el monopolio de la potestad normativa, comparte las competencias de ejecución administrativa y tiene atribuida la función de control y fiscalización de la Alcaldía [art. 22.2.a)] la cual puede manifestarse de forma extrema mediante el ejercicio de la moción de censura (art. 22.3). El Alcalde, por contra, en cuanto órgano del Ayuntamiento, es el ejecutor de las decisiones del Pleno, el director de las obras y los servicios, el jefe del personal, etc.

13 MerCadal: op. cil., p. 891. 
Ahora bien, lo anterior no nos debe hacer caer en la tentación de enfocar técnicamente las relaciones entre Pleno y Alcaldía a imagen y semejanza de las existentes entre Parlamento y Gobierno, ni dejar de recordar que el Alcalde ocupa otras dos posiciones adicionales dentro del Ayuntamiento (Presidente del ente constituido por el Ayuntamiento y Presidente del órgano constituido por el Pleno), lo que le dotan de un liderazgo político que propicia la concentración competencial en su figura ${ }^{14}$.

\section{EL ALCALDE EN CUANTO PRESIDENTE DEL AYUNTAMIENTO-ENTE}

Como señala el artículo 21.1 el Alcalde es el Presidente de la Corporación, esto es, de la persona jurídica integrada por los representantes de la colectividad local. En cuanto tal, ostenta la representación del Ayuntamiento [art. 21.1.b)] y es la razón por la cual ostenta la presidencia del resto de los órganos del Ayuntamiento [art. 21.1.c)].

La atribución de la representación del Ayuntamiento sí es, a mi juicio, esencialmente protocolaria y político-institucional, lo cual tiene una importante dimensión en lo que se refiere a la presencia del Ayuntamiento en los órganos de colaboración y en las instancias de participación que puedan crearse (arts. 56, 57 y 58), pero de esta representación no deriva, tal como señalan MORELL ${ }^{15}$ y SANTAMARÍA ${ }^{16}$, que sea el órgano que monopoliza la expresión ante terceros de la volundad del Ayuntamiento. Según se desprende de la construcción realizada para dar coherencia a todos los postulados legales incluidos en la LRBRL y en el Texto Refundido, el Alcalde es el Presidente del Ayuntamiento-ente, pero expresa la voluntad del mismo en base a la otra doble faz de la figura del Alcalde como órgano unipersonal y como Presidente de los demás órganos colegiados. Esta construcción da coherencia conceptual a la consideración de la Alcaldía y del Pleno como órganos, que, según la definición al uso, son aquellas unidades de la organización administrativa con capacidad de imputación jurídica a la

14 Como destaca SANTAMARfa, «trazar un paralelo exacto sería, no obstante exagerado: no hay, en sentido estricto, división de poderes en el seno del Ayuntamiento, en el que el Pleno sigue ostentando numerosas potestades típicamente administrativas (el Pleno es también, pues, un órgano de gestión administrativa); tampoco hay una división del poder normativo en dos niveles subordinados entre sí, como en la esfera estatal (ley-reglamento), por cuanto el Pleno conserva el monopolio de esta porestad. En lo demás, sin embargo, las similitudes son cada vez más acusadas: el Ayuntamiento, por ejemplo, no es ajeno al fenómeno general de liderazgo de los ejecutivos monocráticos, cuyas competencias tienden a acrecentarse en perjuicio de los órganos colegiados de control» (Fundamentos de Derecbo Administrativo, Ed. Ramón Areces, Madrid, 1988, pp. 1141-1142).

15 MORELl, op. cit., p. 569.

16 Santamaría, op. cit., p. 1141. 
persona-ente ${ }^{17}$. La prueba normativa de lo anterior nos lo proporciona el artículo 52.2 LRBRL en donde se atribuye al Pleno como «órgano», el que sus resoluciones pongan fin a la vía administrativa.

Sin embargo, quizás esta posición de Presidente de la Corporación, sí sea una explicación para la posterior atribución a la Alcaldía, como órgano unipersonal, de las competencias residuales [art. 21.1.m)].

\section{EL ALCALDE EN CUANTO TITULAR DEL ORGANO DE DIRECCION GUBERNATIVA Y ADMINISTRATIVA DEL AYUNTAMIENTO}

\section{A) CLÁusula GENERAl DE ATRIBUCIÓN DE FUNCIONES DIRECTIVAS}

Ya se ha señalado anteriormente que no cabe hablar del Alcalde como órgano ejecutivo, desde el momento que también el Pleno ostenta competencias puramente administrativas. Sin embargo, el artículo 21.1.a) LRBRL le atribuye al Alcalde, de modo general, la dirección del gobierno y la administración municipal, lo que MORELL considera «la clave de la posición del Alcalde» ${ }^{18} \mathrm{y}$, al mismo tiempo, el artículo 22.1.a) LRBRL atribuye al Pleno el control y fiscalización de los órganos de gobierno.

En base a esta cláusula de atribución general, el Alcalde recibe un triple orden de competencias relativas a la actividad interna de la Corporación, a su actividad externa frente a terceros y a la formación de su equipo de gobierno ${ }^{19}$.

\section{B) COMPETENCIAS RELATIVAS A LA ACTIVIDAD INTERNA DE LA CORPORACIÓN}

Podemos encuadrar en tres bloques temáticos las competencias de gestión interna del Alcalde, aquellas relativas a los servicios, las relativas al personal y las relativas a las actividades económico-financieras. 


\section{a) Servicios}

La primera categoría cuenta con una cláusula general en el apartado d) del artículo 21.1 LRBRL, «dirigir, inspeccionar e impulsar los servicios y obras municipales». Esta competencia, que es delegable, se completa con lo establecido en el artículo 24.b) del Texto Refundido, que le atribuye al Alcalde «la organización de los servicios administrativos de la Corporación, en el marco del Reglamento Orgánico. De forma expresa se le atribuye la jefatura de la policía municipal [art. 21.1.b)] y se le otorga la potestad de adopción, bajo su responsabilidad personal, de las medidas que entienda que son necesarias y adecuadas para hacer frente a situaciones de catástrofe o infortunio público o de grave riesgo de que éstas se produzcan. Esta competencia no es delegable y de su ejercicio debe dar cuenta inmediata al Pleno [art. 21.1.j)]. Según SANTAMARÍA ${ }^{20}$, estas dos últimas competencias son residuos de su «antigua condición histórica de órgano estatal y delegado del Gobierno», aunque hoy día las ostenta en cuanto director del gobierno municipal $^{21}$.

\section{b) Personal}

En materia de personal, el Alcalde desempeña la jefatura superior de todo, personal de la Corporación [art. 21.1.g) LRBRL], competencia no delegable y que ostenta con carácter residual respecto de las del Pleno en base a lo dispuesto en el artículo 24.d) del Texto Refundido. De forma expresa, la LRBRL le atribuye el nombramiento y sanción de los funcionarios que usen armas [art. 21.1.b)].

\section{c) Economia y finanzas}

Las competencias en el terreno económico-financiero se refieren a «disponer gastos, dentro de los límites de su competencia: ordenar pagos y rendir cuentas» [art. 21.1.f) LRBRL], lo que se completa con lo dispuesto en el artículo 24.f) del Texto Refundido que le atribuye «el desarrollo y la gestión económica conforme al presupuesto aprobado». También ostenta competencias de contratación de obras y servicios

20 SANTAMARIA, op. cil., p. 1141.

21 En el mismo sentido se manifiesta MORELL, para el cual la LRBRL, «deja al margen la conexión con la autoridad estatal en lo concerniente a la protección de la seguridad pública, en cuanto cometido propio de la legalidad sectorial correspondiente, que será la que igualmente determine la función del Municipio en esta materia», op. cit., p. 571. 
siempre que su cuantía no exceda del 5 por 100 de los recursos ordinarios de su presupuesto ni del 50 por 100 del límite general aplicable a la contratación directa, facultades que el artículo 24.c) del Texto Refundido extiende a aquellos contratos que tengan una duración no superior a un año o no exijan créditos superiores al consignado en el presupuesto anual. El apartado $f$ ) de este último precepto completa estas competencias mediante la atribución de la presidencia de las subastas y concursos para ventas, arrendamientos, suministros y toda clase de adjudicaciones de servicios y obras municipales.

\section{C) COMPETENCIAS RELATIVAS A LAS RELACIONES EXTERNAS DE LA CORPORACIÓN}

En base a la construcción antes expuesta, el Alcalde es un órgano del Ayuntamiento y, en cuanto tal, con capacidad de imputación al ente local de sus manifestaciones de voluntad. Esta capacidad de imputación está limitada a su estricto ámbito competencial. Así lo prueba su competencia para la interposición de acciones judiciales y administrativas, que sólo puede ejercer en casos de urgencia [art. 21.1.i)], o la de sancionar las faltas de desobediencia a su autoridad o por infracción de las Ordenanzas municipales, que lo hace salvo en los casos en que tal facultad esté atribuida a otros órganos [art. 21.1.k)] o el otorgamiento de licencias que se produce sólo cuando así lo dispongan las Ordenanzas (art. $\mathrm{d} 21.1 .11)^{22}$. Estas competencias materiales dirigidas hacia el exterior de la Corporación no deben confundirse con otras competencias instrumentales, en tanto que director de los servicios administrativos, de dar publicidad o ejecutar los actos de la Corporación que puedan ser emanados por otros órganos. En este sentido el artículo 21.1.e) LRBRL le atribuye la competencia de dictar bandos y el artículo 24.g) del Texto Refundido le atribuye las de publicar, ejecutar y hacer cumplir los acuerdos del Ayuntamiento.

\section{D) COMPETENCIAS RELATIVAS A LA FORMACIÓN DE SU EQUIPO DE GOBIERNO}

Al Alcalde le asisten también un conjunto de competencias organizativas encaminadas a la formación de su equipo de gobierno. Estas

22 Esta competencia aparece transformada en el Texto Refundido, cuyo artículo 24.e) atribuye al Alcalde la concesión de licencias como criterio general, «salvo que las Ordenanzas o las Leyes sectoriales la atribuyan expresamente al Pleno o a la Comisión de Gobierno». Dicha transformación, no hace, en el fondo, sino reproducir la cláusula general de atribución residual de competencias en favor del Alcalde contenida en el artículo 21.1.m) LRBRL. 
competencias son básicamente tres: nombramiento de los miembros de la Comisión de Gobierno, nombramiento de los Tenientes de Alcalde y la facultad de delegación de sus propias competencias.

La figura de la Comisión de Gobierno, que no nos corresponde analizar, tiene como cometido básico la asistencia al Alcalde en el ejercicio de sus atribuciones y le corresponde a éste el libre nombramiento y separación de sus miembros que deben ostentar la condición de Concejales (art. 23.1 y 2 LRBRL). Se concreta, así, una diferencia, ya comúnmente señalada, del carácter representativo del gobierno municipal, no pudiendo el Alcalde designar para dicho órgano a personas que no hayan sido elegidas por la colectividad para formar parte de la Corporación.

De entre los miembros de la Comisión del Gobierno, el Alcalde puede también designar y revocar libremente a los Tenientes de $\mathrm{Al}$ calde, que además de sus cometidos en el seno de dicha Comisión, tienen como misión específica la sustitución, por su orden de nombramiento, del Alcalde en los casos de vacante, ausencia o enfermedad. Allí donde no exista Comisión de Gobierno, nombra los Tenientes de Alcalde de entre Concejales (art. 23.3 LRBRL).

Finalmente, las posibilidades organizativas del Alcalde se completan con un juego muy flexible de la técnica de la delegación, ya que ésta se puede producir en favor de la Comisión de Gobierno [art. 23.2.b) LRBRL]; de los miembros de la Comisión de Gobierno, sean o no Tenientes de Alcalde; de los Tenientes de Alcalde cuando no exista Comisión del Gobierno; y de cualquier Concejal aunque no pertenezca a la Comisión de Gobierno. No cabe duda que estas amplias facultades de delegación suponen una vía de escape a la tremenda concentración de tareas que descansan en el Alcalde como vértice de la pirámide de la administración municipal. Pero, al mismo tiempo, estamos ante una técnica organizativa articulada en base a una concentración competencial, a la que se acompaña de una flexibilización delegativa para concluir en una posición fáctica de dirección muy reforzada por la permanente posibilidad de recuperar el ejercicio directo de la competencia o hacer recaer la delegación en otro colaborador. La regla es de una gran simplicidad, pero tiene la virtud de su adaptabilidad a las innumerables situaciones concretas de los ocho mil $\mathrm{Mu}$ nicipios españoles.

\section{EL ALCALDE COMO MIEMBRO-PRESIDENTE DE LOS ORGANOS COLEGIADOS MUNICIPALES}

En tanto que Concejal, el Alcalde es miembro de la Corporación Municipal y, por ende, del órgano colegiado que reúne a la totalidad 
de sus miembros. Ahora bien, su Presidencia podría explicarse de un doble modo. De un lado, el conjunto de los Concejales tendrían la potestad de elegir a su propio Presidente el cual, al tiempo, y a causa de la legislación electoral, ostenta también el cargo de Alcalde. De otro, los Concejales tendrían como uno de sus deberes la de proceder a elegir de entre sus miembros al titular del órgano de la Alcaldía, el cual, por mandato legal, ostenta la Presidencia. El dilema sólo tiene utilidad desde la perspectiva constitucional. En efecto, el artículo 140 contempla una diferenciación entre Alcalde y Concejales y consiente la elección directa del Alcalde por los vecinos. Ello podría dar lugar a una Alcaldía presidencialista, separada del Pleno, con multitud de posibilidades de desarrollo legislativo, entre las que se podría encontrar una presidencia de Pleno atribuida a una elección interna de entre los Concejales elegidos y que, por tanto, podría no recaer en el Alcalde por no ser éste Concejal. Por ello, es más acorde con la Constitución la configuración de la Alcaldía como un órgano separado del Pleno ${ }^{23}$.

Este rasgo constitucional se completa en LRBRL con la atribución al Alcalde de la Presidencia de la Corporación, por lo que configura la cabeza del elemento ordinamental constituido por la organización municipal que está dotada de personalidad jurídica propia. El actual dato electoral concibe al Alcalde como un Concejal, pero la diferenciación de órganos entre Alcaldía y Pleno que se deriva de la Constitución lleva a la conclusión de que, en el momento de la elección del Alcalde, los Concejales no eligen al Presidente de su Pleno, pues la Constitución no exige al Alcalde el requisito de ser previamente Concejal. Los Concejales eligen al titular de un órgano externo al Pleno, titular que por mandato de la ley electoral debe ser un Concejal; titular que por mandato de la LRBRL es el Presidente del conjunto del Ayuntamiento y que, también por mandato de la LRBRL, y ya dentro de una lógica conclusiva de las dos premisas legales anteriores, es el Presidente de todos los órganos colegiados del Ayuntamiento.

Qué duda cabe que la ostentación de la Presidencia sigue reforzando la posición central del Alcalde en el seno del Ayuntamiento. Sus potestades de convocatoria de las sesiones ordinarias y extraordinarias [art. 46.2.a) LRBRL], su imprescindible asistencia para la válida constitución del Pleno [art. 46.2.c) LRBRL], su voto de calidad [art. 46.2, in fine, LRBRL], su facultad de sometimiento a informe del Secretario

23 Una reflexión similar es la de MORelL, para el cual «en la presente circunstancia, y aunque se conserva la posibilidad de que el legislador diferencie al Presidente del Pleno - si se decidiese a la elección directa por el vecindario- la Ley básica advierte los términos de la cuestión. Es Presidente el Alcalde, pero éste es un miembro del Pleno, y ostentará el cargo mientras conserve la confianza del propio Pleno. Podria seguirse afirmando que la presidencia del Pleno es cargo anejo a la Alcaldía, pero que sea exterior al Pleno. En todo caso, esa identidad personal en los dos cargos se explica ahora mejor si se tiene en cuenta que el titular es Presidente de la Corporación», op. cit., p. 586. 
y/o del Interventor de cuantos asuntos considere oportunos [art. 54.1.a) TR] y la de rúbrica de los actos del Pleno (art. 52.1 TR), le otorgan importantes medios de dirección y programación de la actividad del Pleno.

Respecto de su presidencia de la Comisión de Gobierno, aunque se le haya dotado, a través del Reglamento de Organización y Funcionamiento, de una procedimentalización de sus actuaciones, la posición política del Alcalde respecto a sus miembros es de tal magnitud que su funcionalidad interna está lejos de poder/deber ser plenamente juridificada. No en vano la LRBRL omite cualquier regla al respecto.

\section{CONCLUSIONES}

En este análisis de la figura del Alcalde hemos podido extraer algunas conclusiones que pueden tener algún interés, desde el punto de vista la dogmática de la organización local.

Nuestra Constitución y la LRBRL han procedido a una doble entificación del Municipio como ordenamiento territorial y del Ayuntamiento como organización de dicho ordenamiento. Esta organización se desdobla en dos órganos principales Alcaldía y Pleno. Lo característico del Alcalde es ocupar una triple unión de cargos: Presidente de la Corporación, titular de la Alcaldía y Presidente del resto de los órganos colegiados del Ayuntamiento, entre los que destaca el Pleno.

Como Presidente de la Corporación efectúa una representación político-institucional hacia al exterior, especialmente cuando la legislación sólo se refiera al Municipio como ordenamiento.

En cuanto titular de la Alcaldía destaca la técnica de la concentración competencial, acompañada de una gran flexibilización de la facultad de delegación, lo que le permite situarse en una posición fáctica de dirección, reforzada por la posibilidad de recuperar el ejercicio directo de la competencia.

En fin, en cuanto a su carácter de Presidente del Pleno, aquí se aboga por una construcción de externalidad, basada en las diferentes posibilidades amparadas por el Texto Constitucional. 